\title{
Characterization of Magnesium Doped Lithium Iron Silicate
}

\author{
Juan A. Jaén, ${ }^{1, *}$ Josefina Iglesias, ${ }^{2}$ Alcides Muñoz, ${ }^{3}$ Jesús A. Tabares, ${ }^{4}$ Germán A. Pérez Alcázar ${ }^{4}$
}

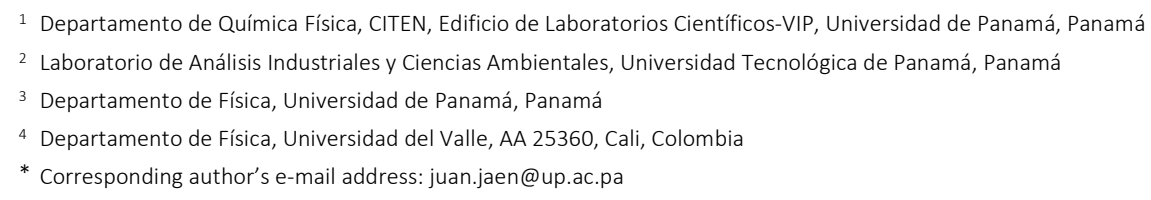

RECEIVED: September 30, 2015 * REVISED: December 23, 2015 * ACCEPTED: December 24, 2015

Abstract: The synthesis of $\mathrm{Mg}$ doped $\mathrm{Li}_{2} \mathrm{Fe}_{1-x} \mathrm{Mg}_{x} \mathrm{SiO}_{4}(x=0,0.10$ and 0.15$)$ via solid-state reaction is reported. The product was characterized by Mössbauer spectroscopy (MS), X-ray diffraction (XRD), Fourier transform infrared spectroscopy (FTIR), magnetic measurements and scanning electron microscopy (SEM). The structures of the reaction products were confirmed to be the monoclinic structure $P 2_{1} / n$, but impurities were detected in them. In the undoped sample small amounts of lithium iron oxide or lithiated magnetite was obtained, whereas a magnetic phase was found in samples with more than $10 \%$ (mole fraction) of $\mathrm{Mg}$ doping.

Keywords: lithium iron silicate, cathode material, Mg doping, Mössbauer spectroscopy.

\section{INTRODUCTION}

S INCE it was proposed in 2005 by Nytén et al., ${ }^{[1]}$ lithium iron silicate $\left(\mathrm{Li}_{2} \mathrm{FeSiO}_{4}\right)$ has drawn considerable attention as one of the most promising cathode materials for lithium-ion batteries. This material is environmentally friendly, made from naturally occurring elements, safe, and has good operating voltage, energy storage capability and high cycling stability. However, it has limited electrical conductivity, and slow Li transport. [2] To overcome these shortcomings numerous alternatives have been proposed, among them doping with an isovalent cation. ${ }^{[3-6]}$

In recent work, Zhang et al. ${ }^{[7]}$ reported the results of the partial substitution of iron by magnesium (up to $3 \%$, mole fraction) in the monoclinic structure (space group: $P 2_{1}$ ) using a sol-gel synthesis method, without destroying the structure of the orthosilicate, and improving the electrochemical properties of the $\mathrm{Li}_{2} \mathrm{FeSiO}_{4}$ cathode materials. Resulting compound, $\mathrm{Li}_{2} \mathrm{Fe}_{0.97} \mathrm{Mg}_{0.3} \mathrm{SiO}_{4}$, exhibits a better cycle stability and reversibility, than the one from undoped $\mathrm{Li}_{2} \mathrm{FeSiO}_{4}$. Huang et al. ${ }^{[8]}$ also reported on composites $\mathrm{Li}_{2} \mathrm{Fe}_{0.97} \mathrm{Mg}_{0.3} \mathrm{SiO}_{4}$ but with the orthorhombic structure indexed to the $P m n 2_{1}$ space group. Similar good electrochemical properties were reported for uniform nano-sized pure $\mathrm{Li}_{2} \mathrm{Fe}_{0.45} \mathrm{Mn}_{0.45} \mathrm{Mg}_{0.1} \mathrm{SiO}_{4}$ by hydrothermal method followed by carbon coating. ${ }^{\text {[9] }}$ $\mathrm{Mg}$ doping also has been successfully used in the olivine cathode materials nano-sized $\mathrm{LiFe}_{1-x} \mathrm{Mg}_{x} \mathrm{PO}_{4}-\mathrm{C}$ $\left(x=0.00,0.02,0.04,0.06\right.$ and 0.08). ${ }^{[10]}$ Mg-doped $\mathrm{LiFe}_{0.96} \mathrm{Mg}_{0.04} \mathrm{PO}_{4}-\mathrm{C}$ has a remarkable effect on improving the electronic or ionic mobility, but serious electrochemical degradation can occur when its doping density is above 0.04 mol.

In this work, the effect of doping with different $\mathrm{Mg}$ mole fractions $(0.00-0.15 \mathrm{~mol})$ on the structure of the orthosilicate prepared via a solid-state reaction was investigated using X-ray diffraction (XRD), Mössbauer spectroscopy (MS), Fourier transform infrared spectroscopy (FTIR), scanning electron microscopy (SEM), and magnetization measurements. Mössbauer spectroscopy is suitable for providing information on the microscopic structure of iron containing materials. 


\section{EXPERIMENTAL SECTION}

Lithium metasilicate $\mathrm{Li}_{2} \mathrm{SiO}_{3}$ (GFS Chemicals, $\geq 99.5 \%$ ), dihydrated iron oxalate $\mathrm{FeC}_{2} \mathrm{O}_{4} \cdot 2 \mathrm{H}_{2} \mathrm{O}$ (Aldrich Chemicals, $99 \%$ ) and tetrahydrated magnesium acetate $\mathrm{Mg}\left(\mathrm{C}_{2} \mathrm{H}_{3} \mathrm{O}_{2}\right)_{2} \cdot 4 \mathrm{H}_{2} \mathrm{O}$ (GFS Chemicals, $\geq 99.9 \%$ ) were mixed in stoichiometric amounts. Different amounts of magnesium were used in order to obtain $0,5,10$, and $15 \%$ (mole fraction) of magnesium-doped orthosilicates $\mathrm{Li}_{2} \mathrm{Fe}_{1-x} \mathrm{Mg}_{x} \mathrm{SiO}_{4}$. The mixture was ground in a planetary mill, model "Pulverisette $5^{\prime \prime}$, for 36 hours, at a frequency of $5 \mathrm{~Hz}$ and a vacuum of $2 \times$ $10^{-5} \mathrm{bar}$. Then, the dried mixture was pelleted at a pressure of $750 \mathrm{psi}\left(5.17 \times 10^{6} \mathrm{~Pa}\right)$ and heated in a horizontal quartz tube oven Hoskins FD303A to $650{ }^{\circ} \mathrm{C}$ at $10{ }^{\circ} \mathrm{C} / \mathrm{min}$. The process was conducted with an argon flow for a period of 12 hours, after which it was cooled at a rate of $-10^{\circ} \mathrm{C} / \mathrm{min}$ to room temperature.

The crystallographic structural characterization of samples was analyzed by X-ray diffraction (XRD, PANalytical $X$ 'Pert powder diffractometer, $\mathrm{Cu} \mathrm{K} \alpha$ radiation). All XRD measurements were carried out at room temperature (298 K) in the range of $10^{\circ} \leq 2 \theta \leq 90^{\circ}$ at intervals of $0.02^{\circ}$, in BraggBrentano geometry. The Rietveld refinement of the XRD patterns were made with the GSAS software, ${ }^{[11]}$ based on a Pseudo Voigt profile function (0.75 0.25 Lorentzian and Gaussian). The cell parameters were determined by fullpattern refinement from the XRD data using the GSAS Software. Crystallographic information files (CIF) of $\mathrm{Li}_{2} \mathrm{FeSiO}_{4}$ were generated from the structural results reported by Mali et al. ${ }^{[12]}$ and Sirisopanaporn et al. ${ }^{[13]}$

Mössbauer spectra (MS) were recorded using a conventional spectrometer of constant acceleration with a ${ }^{57} \mathrm{Co}(\mathrm{Rh})$ source of activity of 5-10 $\mathrm{mCi}(185-370 \mathrm{MBq})$. The measurements were performed at $298 \mathrm{~K}$. The spectra were recorded in transmission geometry. The velocity and isomer shifts were calibrated with an $\alpha$-Fe foil standard. Spectra were fitted using a standard least-squares fitting routine with Lorentzian lines with the Recoil software (University of Ottawa, Canada).

IR spectra were recorded in transmittance mode using a Shimadzu IR-Affinity-1 (FT-IR 8400S) spectrometer. The resolution of the spectra was $4 \mathrm{~cm}^{-1}$. The spectra obtained were handled with software Academic Know It All.
The morphology of the samples was examined using a JEOL JSM-5600 scanning electron microscope (SEM), equipped with an energy-dispersive X-ray (EDX) detector, and operated at an accelerating voltage of 15 and $20 \mathrm{kV}$. The magnetization was measured using a Vibrating Sample Magnetometer (VSM) (Quantum Design PPMS VSM P525).

\section{RESULTS AND DISCUSSION}

XRD patterns of all samples are shown in Figure 1. A full Rietveld refinement was carried out showing that the dominant crystal phases of all the samples are the monoclinic structure $P 2_{1} / n$. The pristine undoped sample has an extra reflection at $42.87^{\circ}$, as shown in Figure $1 \mathrm{e}$, indicating an impurity, which is attributed to lithium iron (III) oxide. [14] The $\mathrm{Mg}$-doped samples gave patterns similar to those of the undoped $\mathrm{Li}_{2} \mathrm{FeSiO}_{4}$. No $\mathrm{Li}_{x} \mathrm{Fe}_{2} \mathrm{O}_{3}$ is obtained, but a reflection around $44.6^{\circ}$ (marked with asterisk in Figure 1 and highlighted with a vertical line in Figure 1e) is particularly observed for samples doped with more than $10 \% \mathrm{Mg}$ (mole fraction). In that region, pristine $\mathrm{Li}_{2} \mathrm{FeSiO}_{4}$ shows some consecutive weak diffraction peaks, but the pattern profiles suggest the contribution of another phase. This reflection matches the (001) characteristic peak of metallic iron, reported as an impurity phase in $\mathrm{Li}_{2} \mathrm{FeSiO}_{4} / \mathrm{C}$ material prepared via a solid-state reaction process. ${ }^{[15]}$ Contamination from the extensive milling procedure is excluded, as assessed by weighing the balls before and after each milling. Additional confirmation could be obtained from Mössbauer results discussed later. Very small amounts of other impurities, such as lithium iron (III) catena-disilicate $\mathrm{LiFe}\left(\mathrm{Si}_{2} \mathrm{O}_{6}\right)$, should not be ruled out in the doped orthosilicates. The most prominent Bragg peaks of this compound occur at $29.842^{\circ}$ and $31.295^{\circ}$. A full Rietveld refinement was carried out on the pristine and $\mathrm{Mg}$-doped $\mathrm{Li}_{2} \mathrm{FeSiO}_{4}$ samples, and the refined lattice parameters are listed in Table 1 . The reliability factors $R_{w}$ are $11.9 \%, 11.4 \%, 14.2 \%$ and $12.3 \%$ for the undoped and 5, 10 and $15 \%$ (mole fraction) Mg doped, respectively. There is a certain intensity variation in some lines of the diffractogram that may be related to $\mathrm{Mg}$ entering the crystal lattice of the orthosilicates provoking changes in the structure, site occupation, or the formation of other phases like $\mathrm{LiFeSiO}_{4}$, a delithiated lithium iron

Table 1. Lattice parameters of $\mathrm{Li}_{2} \mathrm{Fe}_{1-x} \mathrm{Mg}_{x} \mathrm{SiO}_{4}(\mathrm{x}=0,0.05,0.10,0.15)$

\begin{tabular}{|c|c|c|c|c|c|}
\hline Sample & $a / \AA$ & $b / \AA$ & $c / \AA$ & $\beta /^{\circ}$ & $V / \AA^{3}$ \\
\hline$X=0$ & 8.2313 & 5.0159 & 8.2331 & 99.214 & 335.712 \\
\hline$x=0.05$ & 8.2238 & 5.0215 & 8.2407 & 99.065 & 336.057 \\
\hline$x=0.10$ & 8.2245 & 5.0145 & 8.2339 & 98.949 & 335.446 \\
\hline$X=0.15$ & 8.2231 & 5.0170 & 8.2449 & 98.892 & 336.058 \\
\hline
\end{tabular}



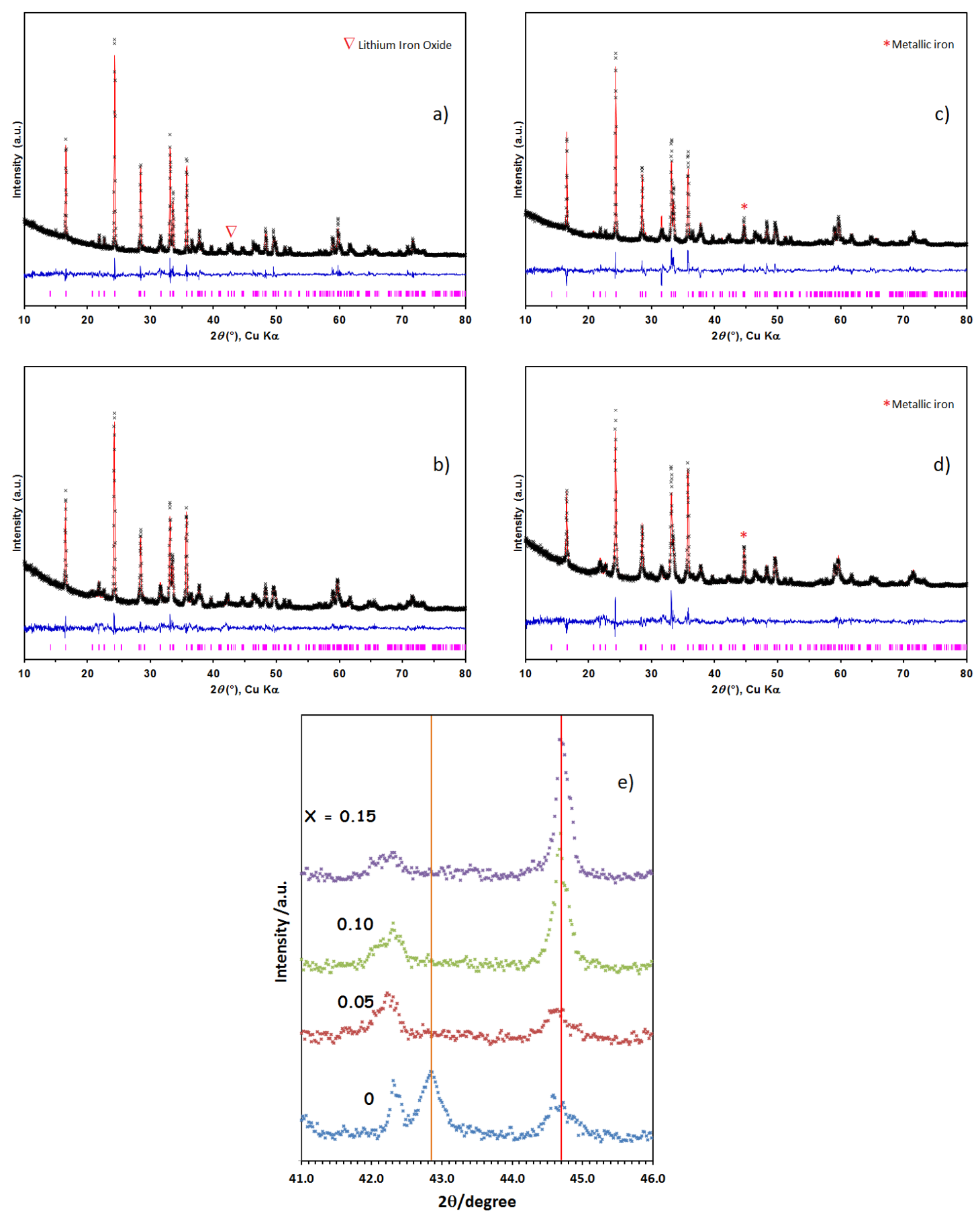

Figure 1. Experimental XRD patterns ( $x$ marked) compared with the Rietveld-refined profile (solid line) and difference curve of the Mg doped orthosilicates a) $x=0$ b) $x=0.05$ c) $x=0.10$ d) $x=0.15$. The Bragg positions of the orthorhombic space group $P 21 / n$ are given and impurities are denoted. e) Enlarged zones of XRD patterns displaying peaks from $41^{\circ}$ to $46^{\circ}$. The vertical line corresponds to lithium iron (III) oxide[14] (left) and to metallic iron (right).

silicate. Lithium delithiated compound has the same structure as the lithiated silicate with almost the same lattice parameters. The existence of impurities precludes better fittings in Rietveld refinements of XRD data. The lattice parameters and unit cell volume do not give the expected slight decrease after doping with $\mathrm{Mg}$ because of the smaller ionic radius in tetrahedral coordination of $\mathrm{Mg}^{2+}(0.57 \AA)$ compared with that of $\mathrm{Fe}^{2+}(0.63 \AA)$. In a previous work, ${ }^{[16]}$ 

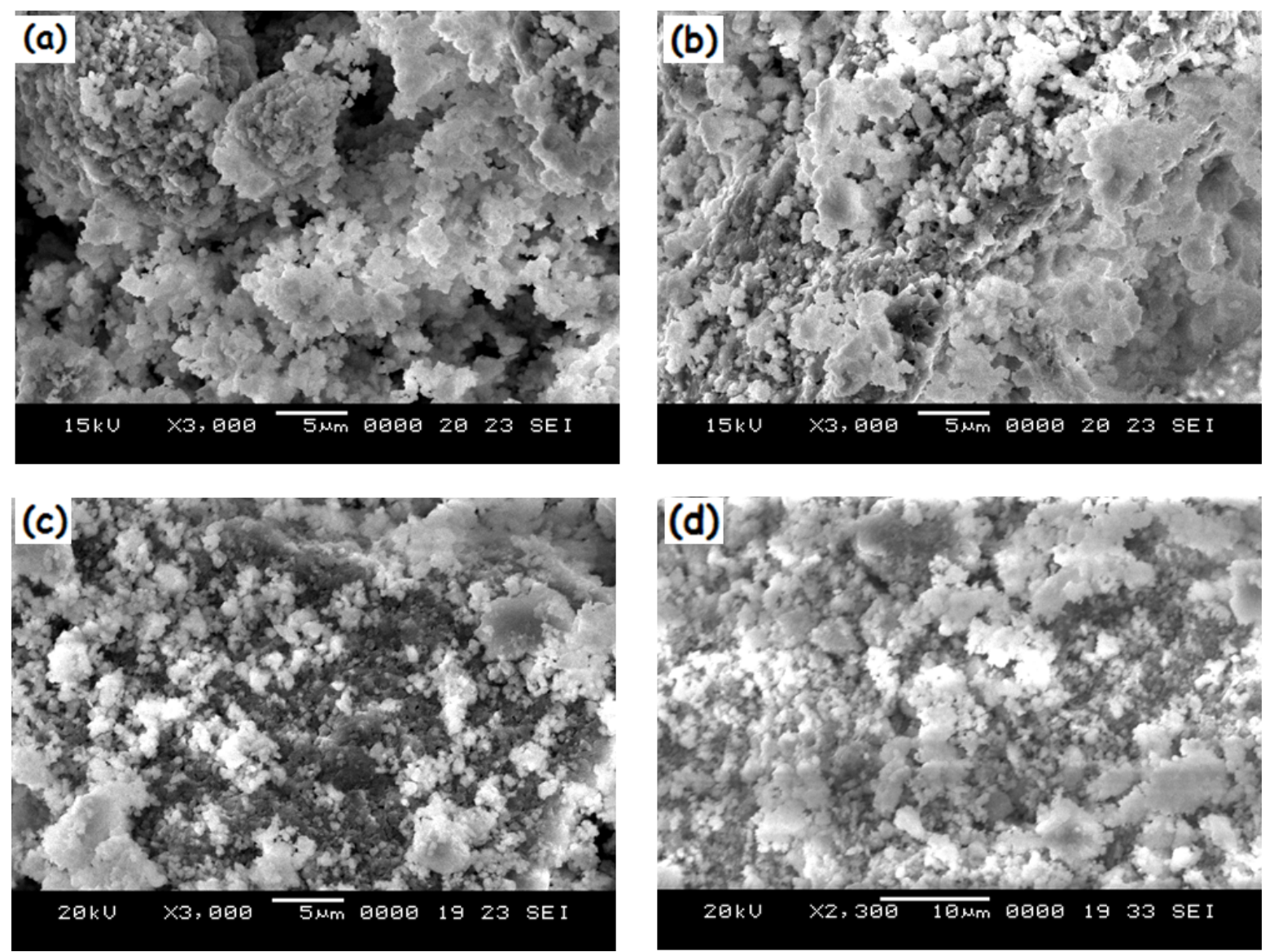

Figure 2. SEM images of $\mathrm{Li}_{2} \mathrm{Fe}_{1-x} \mathrm{Mg}_{x} \mathrm{SiO}_{4}$ (a) $x=0$ (b) $x=0.05$ (c) $x=0.10$ (d) $x=0.15$.

an opposite trend to the one expected using $\mathrm{Ni}$ as dopant was observed. It was argued that cation disorder and structural defects introduced during milling process, and delithiation of the orthosilicate, induce lattice expansion. Huang et $a l .{ }^{[8]}$ proposed that Li ions should have been partially substituted by $\mathrm{Mg}$ ions in the orthorhombic polymorph.

Figure 2 shows the SEM images of prepared orthosilicates. As shown, all the samples are composed of agglomerated small sphere-like particles with a broad micrometersize distribution. Magnesium doping does not make apparent changes in the morphology, but Mg-doped samples show somewhat less agglomeration. The crystallite size calculated from the Scherrer's equation on the XRD patterns was determined to be 181.9, 119.6, 150.0, and $76.5 \mathrm{~nm}$ for the undoped, 5, 10 and $15 \%$ (mole fraction) for $\mathrm{Mg}$ doped, respectively.

Mössbauer spectroscopy measurements at room temperature of all samples are shown in Figure 3. Regardless of the sample, a dominant symmetric doublet is observed, with hyperfine parameters given in Table 2, typical for high-spin $\mathrm{Fe}^{2+}$ in ionic compounds of tetrahedral

Table 2. Room temperature Mössbauer results of major doublet in the Mg doped orthosilicate samples.

\begin{tabular}{ccccc}
\hline $\begin{array}{c}\text { Amount of } \\
\text { Mg doping / mol\% }\end{array}$ & $\mathrm{CS} / \mathrm{mm} \mathrm{s}^{-1}$ & $\mathrm{QS} / \mathrm{mm} \mathrm{s}^{-1}$ & $\mathrm{HWHM} / \mathrm{mm} \mathrm{s}^{-1}$ & $\mathrm{~A} / \%$ \\
\hline 0 & $0.939(2)$ & $2.374(4)$ & $0.180(3)$ & 90.4 \\
5 & $0.940(2)$ & $2.394(4)$ & $0.202(3)$ & 91.2 \\
10 & $0.952(1)$ & $2.407(4)$ & $0.171(3)$ & 85.7 \\
15 & $0.948(2)$ & $2.437(4)$ & $0.187(3)$ & 83.8 \\
\hline
\end{tabular}




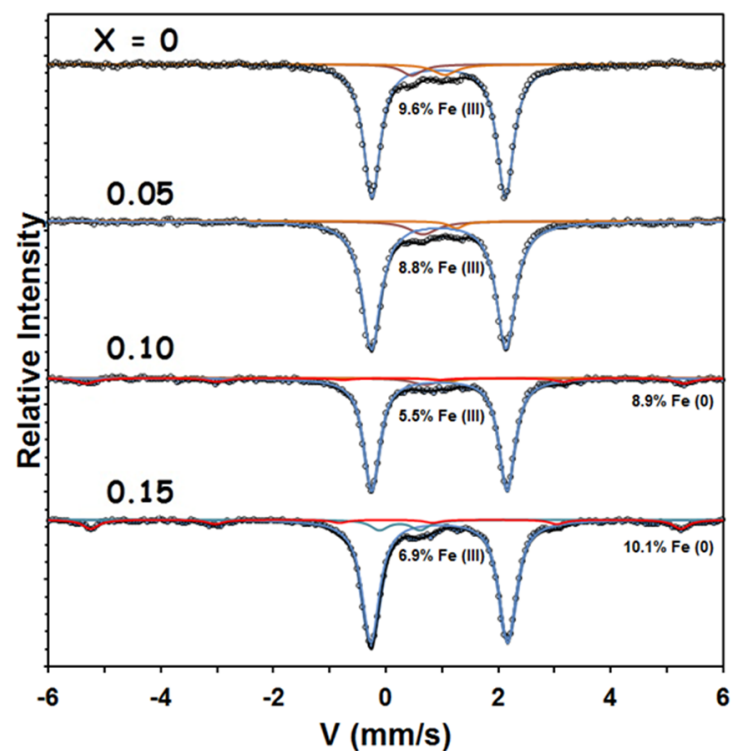

Figure 3. Room temperature Mössbauer spectra of $\mathrm{Mg}$ doped orthosilicate samples.

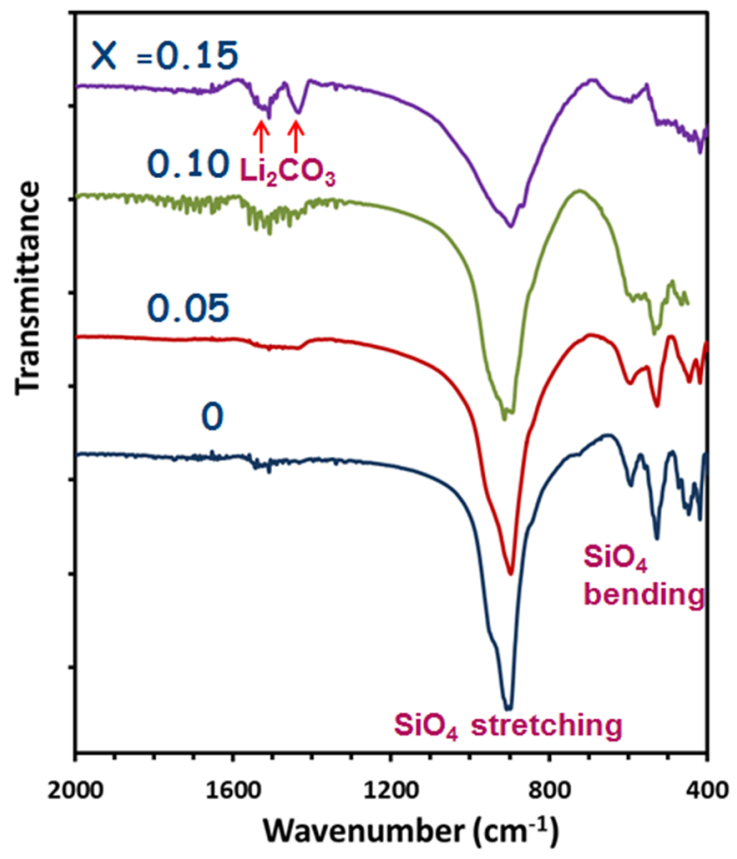

Figure 4. FTIR spectra of $\mathrm{Mg}$ doped $\mathrm{Li}_{2} \mathrm{FeSiO}_{4}$ samples. Peaks at $1431 \mathrm{~cm}^{-1}$ and $1500 \mathrm{~cm}^{-1}$ are attributed to $\mathrm{Li}_{2} \mathrm{CO}_{3}$ formed at the surface.

environment. Of the different polymorphs of $\mathrm{Li}_{2} \mathrm{FeSiO}_{4}$ proposed, the isomer shift and quadrupole splitting values of both, the pristine and doped materials, match with those of the monoclinic structure $P 2_{1} / n .^{[17-21]}$ This result is supported by the XRD and FTIR analysis. The quadrupole

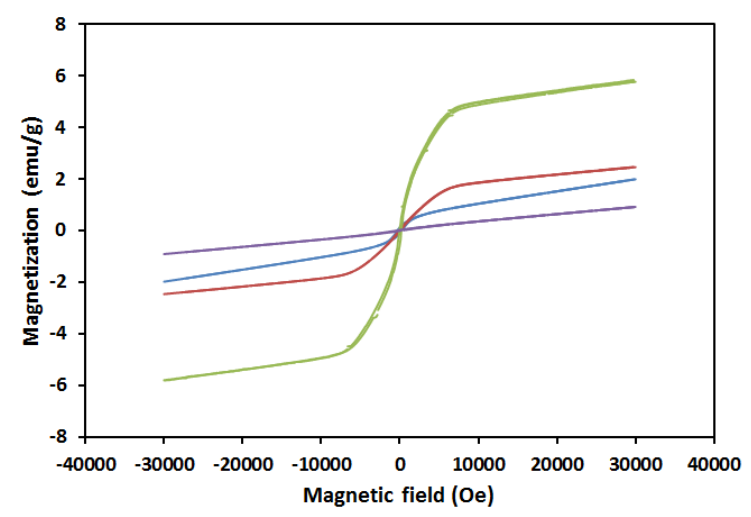

Figure 5. Room temperature magnetization curves of $\mathrm{Li}_{2} \mathrm{Fe}_{1}$ ${ }_{x} \mathrm{Mg}_{x} \mathrm{SiO}_{4}, 0 \leq x \leq 0.15$.

splitting was found to increase monotonically with increasing Mg content, suggesting a diminishing distortion of the iron sites. As pointed out by Mali et al., ${ }^{[12]}$ the quadrupole splitting values can be correlated to the distortion of the $\mathrm{FeO}_{4}$ tetrahedra, with a trend of larger quadrupole splitting for lesser distortion. In addition to the $\mathrm{Fe}^{2+}$ doublet, a small absorption area in the center of each of the Mössbauer spectrum was also observed, associated with a $\mathrm{Fe}^{3+}$ phase. The central resonance absorption in the Mössbauer spectra of undoped and Mg-doped samples up to $10 \%$ (mole fraction) were fitted with two broad singlets which are attributed to nanoparticles of lithiated iron oxides, ${ }^{[21,22]}$ whereas in the case of the $15 \%$ (mole fraction) sample a doublet was used, corresponding to delithiated orthosilicate $\mathrm{LiFeSiO}_{4}{ }^{[23,24]}$ These impurities are imperceptible or hardly detected by XRD or in the FTIR spectra. It is important to note that, disregarding the fitting model used for the Mössbauer spectra, the hyperfine parameters of the $\mathrm{Fe}^{2+}$ doublet remain unchanged. A small contribution from a sextet is observed for samples with equal or exceeding $10 \%$ (mole fraction) doping metal. Data clearly show that $\mathrm{Mg}$ doping is accompanied by reduction of $\mathrm{Fe}^{2+}$ to $\mathrm{BCC}$ iron (saturated solid solution of magnesium in iron [25]), with a Mössbauer hyperfine field varying from 32.9 $\mathrm{T}$ to 32.5 $\mathrm{T}$. An increase in $\mathrm{Mg}$ doping causes segregation of a magnetic phase. There is a monotonic increase of this magnetic phase in samples with more than $10 \%$ (mole fraction) $\mathrm{Mg}$ doping, according to results that are not presented here.

FTIR spectra, shown in Figure 4, have all the attributes of $\mathrm{Li}_{2} \mathrm{FeSiO}_{4}$. The peak at $907 \mathrm{~cm}^{-1}$ in the undoped orthosilicate can be attributed to the stretching vibration of $\left(\mathrm{SiO}_{4}\right)^{4-}$ group. ${ }^{[26]}$ A slight shift of this band towards lower frequencies i.e. $897 \mathrm{~cm}^{-1}$ might be associated with changes in the local environments because of $\mathrm{Mg}$ doping. The shoulder band observed at around $950 \mathrm{~cm}^{-1}$ is due to $\mathrm{SiO}$ apical stretching vibrations. ${ }^{[27]}$ The peaks below $600 \mathrm{~cm}^{-1}$ 
i.e. $527 \mathrm{~cm}^{-1}$ and $594 \mathrm{~cm}^{-1}$ can be ascribed to the bending vibration of tetrahedra $\left(\mathrm{SiO}_{4}\right)^{4-}$. ${ }^{[28]}$ Peaks at $1431 \mathrm{~cm}^{-1}$ and $1500 \mathrm{~cm}^{-1}$ present in all samples and clearly seen in the $15 \%$ (mole fraction) doped sample, point to some amount of $\mathrm{Li}_{2} \mathrm{CO}_{3}$ formed at the surface due to lithium removal from the original structure caused by oxidation in air. ${ }^{[15,29]}$ The $\mathrm{Li}_{2} \mathrm{CO}_{3}$ phase is not detectable by $\mathrm{X}$-ray diffraction due to its low content and crystallinity. The formation of the delithiated orthosilicate $\mathrm{LiFeSiO}_{4}$ gives a hint on the nature of the $\mathrm{Fe}^{3+}$ detected in the $\mathrm{X}$-ray and Mössbauer measurements. A salient feature of the FTIR spectra shown in Figure 4 is the increasing peak broadening with $\mathrm{Mg}$ doping. Infrared line broadening is frequently observed in $\mathrm{Li}_{2} \mathrm{FeSiO}_{4}$ samples. ${ }^{[30-32]}$ Line broadening has been associated with cation substitutions and ordering in silicate minerals. ${ }^{[33]}$ Vanadium substitution on $\mathrm{Li}_{2} \mathrm{FeSiO}_{4} / \mathrm{C}$ composites, for example, results in significant broadening of infrared lines. ${ }^{[34]}$ In $\mathrm{Li}_{2} \mathrm{Fe}_{1-x} \mathrm{Ba}_{x} \mathrm{SiO}_{4}$ samples, this spectra profile variation is attributed to microstructure and surface morphology of different $\mathrm{Li}_{2} \mathrm{FeSiO}_{4}$ samples. ${ }^{[31]}$

Magnetization curves for $\mathrm{Li}_{2} \mathrm{Fe}_{1-x} \mathrm{Mg}_{x} \mathrm{SiO}_{4}(x=0,0.05$, $0.10,0.15)$ crystalline powders at room temperature, given in Figure 5, indicate a large contribution of a paramagnetic phase, also observed in the Mössbauer spectra as the paramagnetic $\mathrm{Fe}^{+2}$ and $\mathrm{Fe}^{+3}$ sites. No change is observed in the paramagnetic nature of the $\mathrm{Li}_{2} \mathrm{FeSiO}_{4}$ after doping with magnesium. Some soft ferromagnetic or ferrimagnetic component is present in these materials, most likely the metallic iron phase detected by both XRD and Mössbauer. This magnetic component increases with the Mg content, indicating that this atom makes unstable the Fe presence in the original monoclinic structure, and it refines also the nanostructure of this phase. The last aspect was detected by XRD which shows that the mean crystallite size decreases with increasing Mg content. As was proved by SEM measurements the particles are micrometric and agglomerated, and present a spherical shape. In accordance with the obtained crystallite size (nanometric) each particle is polycrystalline. The undoped $\mathrm{Li}_{2} \mathrm{FeSiO}_{4}$ shows a behavior typical of a paramagnetic material in agreement with the results reported by Lv et al. ${ }^{[19]}$

\section{CONCLUSION}

$\mathrm{Mg}$ doped $\mathrm{Li}_{2} \mathrm{FeSiO}_{4}$ was synthesized via a solid-state reaction. Both, pristine and doped materials consist of the monoclinic structure (space group: $P 2_{1} / n$ ) as verified by Mössbauer spectroscopy, X-ray diffraction and FTIR. Some small amounts of electrochemical deleterious $\mathrm{Fe}^{3+}$ impurities, like lithium iron oxide or lithiated magnetite, are obtained for the undoped material. Magnesium doped materials with up to $5 \%$ (mole fraction) $\mathrm{Mg}^{2+}$ retain the paramagnetic monoclinic structure and lattice parameter, which indicates that doping agent gets into the structure of $\mathrm{Li}_{2} \mathrm{FeSiO}_{4}$ without destroying its lattice structure. A magnetic phase is segregated for samples with equal or exceeding $10 \%$ (mole fraction) doping metal. Data clearly show that $\mathrm{Mg}$ doping is accompanied by reduction of $\mathrm{Fe}^{2+}$ to magnetic BCC iron. The SEM images have proved that Mgdoped particles form an agglomerate of small sphere-like particles with a wide particle size distribution. No clear tendency in the lattice parameters and crystallite size is observed after $\mathrm{Mg}^{2+}$ doping.

Acknowledgment. The authors thank SENACYT for the financial support (Grant 75-14-4-COL11-049).

\section{REFERENCES}

[1] A. Nytén, A. Abonimrane, M. Armand, T. Gustafsson, J. O. Thomas, Electrochem. Commun. 2005, 7, 156.

[2] K. C. Kam, T. Gustafsson, J. O. Thomas, Solid State Ionics 2011, 192. 356.

[3] Y. Chen, Y. Zhao, X. An, J. Liu, Y. Dong, C. Ling, Electrochim. Acta 2009, 54, 5844.

[4] C. Deng, S. Zhang, S. Y. Yang, B. L. Fu, J. Ma, J. Power Sources 2011, 196, 386.

[5] B. Shao, I. Taniguchi, J. Power Sources 2012, 199, 278.

[6] Y. S. Li, X. Cheng, Z. Zhang, J. Electrochem. Soc. 2012, 159, A69.

[7] S. Zhang, C. Deng, B. L. Fu, S. Y. Yang, L. Mab, J. Electroanal. Chem. 2010, 644, 150.

[8] X. Huang, H. Chen, H. Li, Q. Yang, S. Zhou, Y. Chen, B. Liu, J. Yang, Appl. Mech. Mater. 2013, 310, 90.

[9] H. Yamashita, S. Ishihara, T. Ogami, Pacific cement research report 2013, 165, 42.

[10] A. Örnek, O Efe, Electrochim. Acta 2015, 166, 338.

[11] A. Larson, R. Von Dreele, General Structure Analysis System (GSAS), Los Alamos National Laboratory Report. LAUR 86-748, 2004.

[12] G. Mali, C. Sirisopanaporn, C. Masquelier, D. Hanzel, R. Dominko, Chem. Mater. 2011, 23, 2735.

[13] C. Sirisopanaporn, C. Masquelier, P. Bruce, A. Armstrong, R. Dominko, J. Am. Chem. Soc. 2011, 133, 1263.

[14] M. Pernet, P. Strobel, B. Bonnet, P. Bordet, Solid State lonics 1993, 66, 259.

[15] P. Zuo, T. Wang, G. Cheng, C. Du, Y. Ma, X. Cheng, G. Yin, J. Solid State Electrochem. 2013, 17, 1955.

[16] J. A. Jaén, M. Jiménez, E. Flores, A. Muñoz, J. A. Tabares, G. A. Pérez Alcázar, Hyperfine Interact. 2015, 232, 127.

[17] D. Jugović, M. Milović, V. N. Ivanovski, M. Avdeev, R. Dominko, B. Jokić, D. Uskoković, J. Power Sources 2014, 265, 75.

[18] G. Mali, C. Sirisopanaporn, C. Masquelier, D. Hanzel, R. Dominko, Chem. Mater. 2011, 23, 2735. 
[19] D. Lv, W. Wen, X. Huang, J. Bai, J. Mi, S. Wu, Y. Yang, J. Mater. Chem. 2011, 21, 9506.

[20] C. Sirisopanaporn, A. Boulineau, D. Hanzel, R. Dominko, B. Budic, A. R. Armstrong, P. G. Bruce, C. Masquelier, Inorg. Chem. 2010, 49, 7446.

[21] R. Dominko, D. E. Conte, D. Hanzel, M. Gaberscek, J. Jamnik, J. Power Sources 2008, 78, 842.

[22] P. Domingues, E. Nuñez, and J. Neto, J. Magn. Magn. Mater. 1991, 96, 101.

[23] J. Fontcuberta, J. Rodríguez, M. L. Pernet, J. B. Goodenough, J. App. Phys. 1986, 59, 1918.

[24] I. K. Lee, S. J., Kim, T. Kouh, C. S. Kim, J. Appl. Phys. 2013, 113, 17E306.

[25] G. A. Dorofeev, E. P., Elsukov, A. L. Ul'yanov, Inorg. Mater. 2004, 40, 690.
[26] J. Bai, Z. Gong, D. Lv, Y. Li, H. Zou, Y. Yang, J. Mater. Chem. 2012, 22, 12128.

[27] R. L. Frost, J. M. Bouzaid, W. N. Martens, B. J. Reddy, J. Raman Spectrosc. 2007, 38, 135.

[28] S. Singh, S. Mitra, Electrochim. Acta 2014, 123, 378.

[29] C. Deng, S. Zhang, Y. Gao, B. Wu, L. Ma, Y. H. Sun, B. L. Fu, Q. Wu, F. L. Liu, Electrochim. Acta 2011, 56, 7327.

[30] R. Fu, Y. Li, H. Yang, Y. Zhang, X. Cheng, J. Electrochem. Soc. 2013, 160, A3048.

[31] C. Kim, G. W. Yoo, J. T. Son, J. Nanosci. Nanotechnol. 2015, 15, 8808.

[32] Y. Xu, W. Shen, A. Zhang, H. Liu, Z. Ma, J. Mater. Chem. A 2014, 2, 12982.

[33] T. Boffa Ballarana, Phase Transit. 2003, 76, 137.

[34] Y. Hong, Z. Ying, C. Xuan, J. Electrochem. 2013, 19, 565. 